\title{
Determinants of TB Case Detection in Nigeria: A Survey
}

\author{
Daniel Okuonghae (Corresponding author) \\ Department of Mathematics, Faculty of Physical Sciences \\ University of Benin, P.M.B. 1154, Benin City, Edo State, Nigeria \\ E-mail: danny.okuonghae@corpus-christi.oxon.org \\ Sunday Omosigho \\ Department of Mathematics, Faculty of Physical Sciences \\ University of Benin, P.M.B. 1154, Benin City, Edo State, Nigeria
}

\begin{abstract}
This paper presents results from a survey carried out in Benin City, Nigeria to determine factors that could enhance the case detection rate for tuberculosis. Studies have shown that while the treatment rate is impressive, notification rates over the last decade have been discouraging. Results from the survey identified four key factors that must be combined to increase case detection rates. These factors are effective awareness programme, active cough identification, associated cost factor for treatment of identified cases, stepping up screening exercises and conducting routine tests at regular intervals especially in high population density areas.
\end{abstract}

Keywords: Tuberculosis, Survey, Case detection

\section{Introduction}

It is estimated that a third of the world's population is infected with Mycobacterium tuberculosis. Of the 1.7 billion people estimated to be infected with TB, 1.3 billion live in developing countries (Ssematimba et.al., 2005) while those infected are responsible for 8 to 12 million active cases of TB and 3 million deaths (Magombedze et.al, 2006; North \& Yu-Jin, 2004; Schluger \& Rom, 1998).

Nigeria experienced upsurge of tuberculosis (TB) cases over the past decade. In 2003, there were 44,184 notifications across the country (WHO, 2005), as compared to an estimated 362,819 new cases. The World Health Organization in its 2007 report estimates TB prevalence in Nigeria to be 536 per 100,000 populations (WHO, 2007). The Nigeria National Programme has adopted the WHO recommended strategy as enshrined in the expanded Directly Observed Treatment Short-course (DOTS) strategy. However, a considerable proportion of the Nigerian population lives in areas still not covered by the DOTS services. In 2005 the DOTS coverage in Nigeria was estimated at 65\% (Okeibunor et.al. 2007; WHO, 2007). Nigeria has been ranked fourth among the 22 countries designated by the WHO as the high-burden countries (HBC) for TB. Nigeria is also said to have the highest number of new TB cases in Africa (Soyinka, 2007; WHO, 2006) having about 300,000 of estimated TB cases recorded each year, which result in 30,000 deaths annually.

With introduction of DOTS in Nigeria, the situation has not improved significantly as detection rate remains at a low $21 \%$ while treatment rate is $59 \%$ in 2003 , which are the lowest levels among the high burden countries (HBC) (WHO, 2006); this even when DOTS coverage increased to about 60\%. As shown in (Okuonghae \& Aihie, 2008), the case detection parameter is extremely crucial to the dynamics of TB in Nigeria, either as a means of reducing a backward bifurcation range in a TB model with exogenous re-infection and thereafter make the reproduction number useful in disease control and reducing the impact of the TB burden by directly reducing the value of the reproduction number.

This work is a descriptive survey carried out in Benin City, Edo State, Nigeria. The aim of the survey was to obtain peoples attitude and knowledge on TB. Most people may not quickly understand the signs and symptoms of TB and this could lead to increases in the incidence of TB in the community even before the index case commences treatment. Knowledge can help in increasing case detection as you can only report what you have an idea of, at most. Information on Peoples attitude and knowledge on TB can be used to increase case detection rate. 
Usually, descriptive epidemiological studies are generally concerned with obtaining information on the distribution and causes of disease in the community. It usually involves survey of the community or specified population and obtains descriptive information such as cause of the disease, the age, sex, occupation, education, socio-economic and cultural habits of the population as well as the environmental factors (Ezenwa, 1985). (Note 1)

\section{Survey}

The works in Okuonghae (2008), Okuonghae \& Aihie (2008) and Okuonghae \& Korobeinikov (2007) has identified case detection as key to the effective functioning of DOTS in Nigeria.

According to the report in WHO (2006), the notification rate of young adults is almost equal to the notification rates of older adults. Hence our focus was on young adults in secondary schools as well as students in a university. The average age of the secondary school students was 16 years, the average age of the university students was 24 years while the average age of the students of a computer college also included in the survey was 30 years. In all, the average age of the respondents in the survey was 23 years. We used a self administered questionnaire in the survey.

\section{Study Area}

We selected different segments of the population in an urban city, Benin City, Edo State, using the simple random sampling technique. We conducted the survey in two secondary schools (One of the school is a government secondary school and the other is a demonstration secondary school of one of the Federal Universities), one computer college, final year students of two faculties in a Federal University and a sample of lecturers from one department in the University. Out of the 553 questionnaires sent out, 450 were returned $(81.4 \%)$.

\section{Questionnaire distribution and collection}

The questionnaires were sent to the various groups in the target city. No financial incentive was offered at all levels and the participants received no preliminary information about the study.

For the secondary schools and the computer college, the teachers of the classes involved were used in sending the questionnaires to the respondents. They also collected the questionnaires. Thus the teachers served as the basic channel of distributing and collecting the answered questionnaires. The researchers carried out the distribution and collecting of the questionnaires to the university students and lecturers involved in the study.

\section{Data Analysis}

The data collected was analyzed using the Statistical toolbox in MATLAB Release 12. We also crosschecked the results using $\mathbf{R}$. We performed a Krustall-Wallis test (a non parametric test) on the results from a group of five questions in order to determine whether there are significant differences in the categorical responses of the respondents on the questions.

\section{Findings}

\subsection{How people get infected with $T B$}

The question asked was, How do people get infected with TB? In the validation survey, $33.1 \%$ of the respondents think people get infected with TB from the air while $47.3 \%$ thinks people get infected by contact with a TB infected person. 19.3\% don't know how people get infected with TB while $0.3 \%$ thinks people get infected with TB from dust.

\subsection{Signs and symptoms of TB}

The question asked was, What signs would you observe to know that someone has TB? $39.1 \%$ of the respondents mentioned at most 3 signs of someone having TB while about $32.2 \%$ were able to mention more than three signs of someone having TB. Also $28.7 \%$ could not mention any symptoms for TB. This is, to our mind, a high proportion of the people in the sample considering the nature of the issue under consideration. Those who mentioned the symptoms included chronic cough as a symptom of tuberculosis.

\subsection{Sources of information on TB.}

The question asked was, From what sources do you get information on TB? $19.8 \%$ of the respondents get their information on TB from health workers, $70 \%$ gets such information from TV and radio, $6.2 \%$ from newspapers and magazine while $4 \%$ from other sources (internet, casual discussions). The electronic media is seen as the most powerful tool for obtaining information on TB among those sampled. 


\subsection{Federal Ministry of Health advertisements on TB}

The question asked was, Have you watched the Federal Ministry of Health advertisement on TB and TB treatment? 46.7\% have watched the Nigerian Federal Ministry of Health advertisement on TB and TB treatment while $53.3 \%$ have not seen the advert. Those who have watched it stated that it was seen on the Nigerian Television Authority (NTA) while about $0.05 \%$ watched it on privately/State owned television stations viz: Silverbird TV- Lagos, RSTV-Port-Harcourt and EBS/ITV-Benin City. It seems the advert is concentrated on the NTA stations. Of those who have not seen the advertisement, $42.7 \%$ claims this was due to lack of electricity while $57.3 \%$ thinks the adverts may not have been featured frequently on TV for them to have seen it. Some of the respondents in this latter group feel government enlightenment programs are more on HIV/AIDS. They insist that there are more adverts on HIV/AIDS than TB.

\subsection{Chronic cough as a sign of TB}

The question asked was, Do you think someone with chronic cough, for at least two weeks, could have tuberculosis? $58.3 \%$ of the respondents think that someone with chronic cough (for at least two weeks) could have TB while $12.4 \%$ thinks otherwise. About $29.3 \%$ of the respondents don't know if someone with chronic cough could have TB. This implies that about half of the population may not be able to use chronic cough as a marker for identifying a likely potential TB case. A study in Odermatt et al. (2007) showed the impressive increase in case detection through the informal use of chronic cough as an identifying characteristic of TB cases in the Lao People's Democratic Republic.

\subsection{TB Notification}

The question asked was, Do you think families with a TB patient may fail to notify the relevant health officials about that person because of the stigma it may bring upon the family? $46.4 \%$ of the respondents thinks families with a TB case may fail to immediately notify the relevant health officials about the case because of the stigma it brings on the family members, $24.4 \%$ thinks otherwise while $29.2 \%$ don't know if such could bring any stigma on the family of the TB case.

\subsection{Cough medicine}

The question asked was, Do you think people should just go to a pharmacy/chemist and buy cough medicine whenever they have cough? $38.2 \%$ of the respondents think people should go to the pharmacy or chemist and buy cough medicine whenever they have cough, $47.6 \%$ thinks it is not right, while $14.2 \%$ don't even know whether people can go over the counter and buy cough medicine. It was further observed that $53.6 \%$ of the respondents thinks making cough medicine a prescription drugs could compel people to see the doctor and possibly carry out medical tests whenever they have persistent cough, $18.4 \%$ thinks making cough medicine a prescription drug it will not compel people to go to the hospital and undergo medical tests while $28 \%$ don't know if making cough medicine prescription drugs could compel people to see the doctor and carry out medical tests if they have persistent cough.

\subsection{Analysis using the Kruskal-Wallis test}

Using the Kruskal-Wallis test, we compared the categorical responses of the respondents to the questions related to the results showed in subsections (6.1), (6.2), (6.3), (6.6) and (6.7). Using the statistical toolbox in MATLAB (and comparing the results using $\mathbf{R}$ ), we see from Table 1 below that the p-value from the Kruskal-Wallis test is 0.8376; a highly significant result. The result of the test also showed that the Kruskal-Wallis chi-squared value is 1.4379 while the degrees of freedom (df) is 4 . Clearly, this shows that the categorical responses of the respondents on the questions whose results are stated in the five subsections listed above are not significantly different; we hereby accept the hypothesis that the responses to the questions are not significantly different. There is consistency in the answers provided by the respondents to the questions under consideration. Hence, respondents with a lack of information on tuberculosis cannot say much on the symptoms and signs of TB and cannot use chronic cough as a marker for identifying a potential TB case which may lead to failure to notify the $\mathrm{TB}$ case to the relevant health authorities.

\section{Discussion of Findings}

The results from the survey showed that many people don't know how someone could get infected with tuberculosis while a vast majority don't know any sign and symptom of TB. This shows that government still has much to do in terms of increased enlightenment campaign on tuberculosis and its treatment. The campaign should be in both the print and electronic media. Flyers and posters on the signs and symptoms of TB and the Federal Government treatment policy on TB should be printed and distributed especially in rural areas. The flyers, posters and billboards should be written in English language and at least in the three major languages in 
Nigeria: Hausa, Igbo and Yoruba. These sources of information should clearly state the signs and symptoms suggestive of tuberculosis which includes cough lasting more than two weeks, unintentional weight loss, loss of appetite, swelling of glands, night fevers and drenching night (Guwatudde et.al. 2003). It is interesting that while a good number of the secondary school students were able to mention more than three signs of TB, only a handful of the respondents from the computer training college could mention at least three symptoms of TB. All respondents included cough as a symptom of TB.

It is very good that people can readily identify a 'potential' TB infectious case using chronic cough as a marker, although about half of the population in the survey either didn't know if chronic cough could be used as a marker for identifying TB cases or disagreed completely with the idea that chronic cough could be a marker for someone with tuberculosis. However the study in Odermatt et al. (2007) showed that actively identifying patients with chronic cough in the community has the potential to improve case detection rates as shown in the study conducted in the Lao People's Democratic Republic. The study suggested that rapid, low-cost and easily applicable approaches are needed for improving detection rates of TB in the locality. In this case, chronic cough is an easily recognizable symptom for laypersons. Basically the objective of the study in Odermatt et al. (2007) was to validate a rapid and low-cost questionnaire to identify patients with chronic cough and assess its relevance in TB case detection in six provinces. The result from the study in Odermatt et al. (2007) showed that the lay informant questionnaire method performed moderately. It allowed the detection of several hitherto undiagnosed smear-positive TB cases. In fact in one of the selected province, nine new TB cases were diagnosed, yielding an incidence rate of $342 / 100,000$, which is three times higher than the national incidence rate. Hence being able to identify a TB infectious case using chronic cough that lasts for more than two weeks as an important marker could help in increasing case detection in Nigeria as many in the population are ready to use such a means of identifying TB cases Odermatt et al. (2007).

Our survey also revealed that a vast majority of members of the surveyed community rely on the electronic media (TV and radio) for their sources of information on TB. This shows that the use of TV and radio for TB enlightenment programmes cannot be overemphasized. It is imperative to state that the survey was carried out in an urban area, where electricity and electronic appliances, like television and radio, are readily available unlike in the rural areas. However, with more rural areas having electricity, the use of TV and radio for TB programs should be greatly encouraged. Even in places where there is no electricity, most rural dwellers have small transistor radios. TB programmes should be featured regularly on radio programs most especially in the local languages of the community. Moreover, it seems the TB enlightenment programme and advertisement under the Nigerian Federal Ministry of Health is shown exclusively on the Nigerian Television Authority (NTA), a Federal Government owned electronic media outfit. Only a few of the respondents mentioned state or privately owned TV stations as airing TB information programmes. It is therefore suggested that TB enlightenment programmes be aired in all TV stations nationwide. Most local TV stations have programs in the local language. This is an excellent platform for informing the local populace about the Federal government policy on TB and TB treatment. Radio stations should also have programmes on tuberculosis. Newspapers should regularly feature commentaries on TB, paid for by the government at all levels.

The TB programmes should be featured regularly as most of the respondents from the survey indicated that they may not have been aware of the Federal Government treatment policy on TB because the advertisement may not have been featured regularly on TV. In fact most of the respondents feel that there is more information on HIV/AIDS than TB in Nigeria. This lapse should be addressed. It should be noted that while HIV is primarily a 'behavioural' disease (a persons behaviour may determine if he gets the disease), TB is airborne and easily contracted by both adults and children irrespective of your behaviour (Sharomi et.al. 2008). Improvement in electricity is greatly encouraged as about $42.7 \%$ of the respondents claimed that they have not seen the TB advert on TV due to lack of electricity.

The survey also revealed that places with a TB case, and especially when there is a recorded death resulting from $\mathrm{TB}$, was not visited by the relevant health officials for screening and contact tracing. This is very disturbing especially if it is a school that is involved. There is a high rate of mixing in schools and an unidentified TB case could well have started the spread of the disease in the school. It is important that schools are screened once the health authorities are notified of a TB case in such a school, even before such a case results in death. Also simple basic preventive measures, such as covering of the mouth when coughing, should be encouraged.

It is important that people carry out medical tests when they experience persistent cough for at least two weeks. The study found out that most people have the tendency in engaging in self-medication when they have persistent cough; they simply go over the counter and procure a cough mixture. Many persons, though, thinks making cough medicines a prescription drug will compel people to see a doctor and undergo medical tests to 
properly diagnose what is wrong with the patient. The Federal Ministry of Health and other relevant health agencies could insist on making cough medicines prescription drugs. Other preliminary measures could be taken as first aid' measures e.g. stop the taking of cold water, as some of the respondents suggested, take more vitamins especially vitamins $\mathrm{C}$ from fruits e.t.c. If symptoms persist, then a doctor should be seen and the individuals should not engage in self-medication, especially when the cough persists.

Notification rates will increase if families readily open up to relevant heath officials about any TB case in the family (46.4\% of respondents thinks families with a TB case may fail to immediately notify the relevant health officials about the TB case because of the stigma it may bring on the family). They should not allow the so-called 'stigma' that could come upon the family prevent them from notifying the health workers about one of their own having tuberculosis. Many agree that stigmatization could prevent families from revealing TB cases to health officials and instead resort to alternative, ineffective measures for treating the disease (measures that may not even deal with the problem), hereby increasing the infectious period of the person and putting other family members at risk of infection.

The study further showed that many agree that the cost of undergoing a thorough and comprehensive TB medical test could prevent them from commencing treatment on time, especially in rural areas. Investigations once revealed that on the average, about N5,000 - N12,000 (Nigerian naira) may be spent on such tests and pre-treatment drugs at a TB specialist hospital in south-western Nigeria, as at 2001; this, even when the actual TB treatment drugs was perceived free since the hospital is under the Government and supported by international agencies. This is quite a big amount considering that the minimum wage in Nigeria then was about N5, 500 and most people in the rural areas may not even be able to afford it. This cost may compel people to resort to alternative means like uncontrolled and unprofessional use of traditional or herbal medicine, hereby increasing the infectious period of the TB patient. We encourage making TB tests, as well as the entire treatment regimen required for a comprehensive and effective cure, free. This will readily make people undertake such tests and treatment for TB if necessary.

The public should also be enlightened about TB medical tests. From the survey, well below $1 \%$ of the total sample size could mention tests such as Mantoux test and sputum test. In fact from some of the sub-sampled population, well over $95 \%$ of the respondents could not mention one TB tests. None mentioned X-ray, a very important TB test. It is therefore important that people are enlightened on TB tests so as to allay their fears about TB and its treatment. We encourage making TB tests, such as the Mantoux test compulsory. Routine tests should be carried out in high density areas like markets, schools e.t.c. In markets, routine tests can be done once a year. At schools and places of employment, TB tests should be made compulsory at 'point of entry' i.e. first year of school or employment. Then the students and the workers should be tested every other year to see if the prevalence and incidence of TB is going down or even spiralling out of control.

Generally, we can say that the studies showed that people could be ignorant of the cause of tuberculosis and as such may not be able to give specific attention to those suffering from the disease. These may adopt alternative such as native medicine until the health condition have worsened before they are presented at the hospital. Hence the likelihood of transmission is already high before the commencement of treatment. Also there could be a high probability of lack of adequate coverage of the population by health workers, especially in relation to screening or contact tracing of persons living with a TB infectious case.

In summary, the key aspects of the conducted survey that could lead to a great improvement in case detection include:

- effective enlightenment or awareness programmes on tuberculosis shown on TV (if possible all TV stations) and featured on radio programmes, use of flyers, posters and billboards to serve as 'vaccine' against TB, for as they say "Knowledge is power",

- actively identifying TB patients with chronic cough lasting more than two weeks,

- making both TB medical tests and treatment free under the federal government TB management policy,

- stepping up screening and contact tracing in places where there are identified TB cases or places where a TB case have died, and

- conducting routine tests in high density areas in the society like markets and schools and conducting the tests at regular intervals in these places.

All of these could go a long way in addressing this very important aspect of tackling tuberculosis in Nigeria: improve on the case detection rate. 


\section{References}

Ezenwa, A. O. (1985). Comprehensive text on community health and safety in the tropics. Safety Sciences, Lagos, Nigeria, (Chapter 8).

Guwatudde, D., Zalwango, S., Kamya, M. R., \& Debanne, S. M. (2003). Burden of tuberculosis in Kampala, Uganda. Bulletin of the World Health Organisation, 81(11), 799-805.

Magombedze, G., Garira, W., \& Mwenje, E. (2006). Modelling the Human Immune Response Mechanisms to Mycobacterium Tuberculosis Infection in the Lungs. Mathematical Biosciences and Engineering, 3 (4), $661-682$.

North, R. J., \& Yu-Jin, J. (2004). Immunity to Tuberculosis. Annual Review of Immunology, 22, 599-623.

Odermatt, P., Nanthaphone, S., Barenes, H., Chanthavysouk, K. et.al. (2007). Improving tuberculosis case detection rate with a lay informant questionnaire: an experience from the Lao Peoples's Democratic Republic. Bulletin of the World Health Organisation, 85(9), 649-732.

Okeibunor, J. C., Onyeneho, N. G., Chukwu, J. N., \& Post, E. (2007). Where do tuberculosis patients go for treatment before reporting to DOTS clinics in southern Nigeria? Tanzania Health Research Bulletin, 9(2), 94-101.

Okuonghae, D. (2008). Modelling the dynamics of tuberculosis in Nigeria. Journal of the Nigerian Association of Mathematical Physics, 12 (1), 417-430.

Okuonghae, D. \& Aihie, V. (2008). Case Detection and Direct Observation Therapy Strategy (DOTS) in Nigeria: Its effect on TB dynamics. Journal of Biological Systems, 16(1), 1-31.

Okuonghae, D. \& Korobeinikov, A. (2007). Dynamics of Tuberculosis: The effect of Direct Observation Therapy Strategy (DOTS) in Nigeria. Mathematical Modelling of Natural Phenomena, 2 (1), 113-128.

Schluger, N. W., \& Rom W. N. (1998). The Host Immune Response to Tuberculosis. American Journal of Respiratory and Critical Care Medicine, 157, 679-691.

Sharomi, O., Podder, C. N., Gumel, A. B., \& Song, B. (2008). Mathematical Analysis of the Transmission Dynamics of HIV/TB Co-infection in the presence of Treatment. Mathematical Biosciences and Engineering, 5(1), 145-74.

Soyinka, A. (2007). Nigeria ranks fourth among TB high-burden countries. The Punch Newspaper, page 3, January 15.

Ssematimba, A., Mugisha, J. Y. T., \& Luboobi, L. S. (2005). Mathematical Models for the Dynamics of Tuberculosis in Density-dependent Populations: The Case of Internally Displaced Peoples Camps (IDPCs) in Uganda, Journal of Mathematics and Statistics, 1 (3), 217-224.

World Health Organisation. (2005). Global Tuberculosis Control: Surveillance, Planning, Financing, World Health Organisation Report, Geneva. WHO/HTM/TB/2005.349.

World Health Organisation. (2006). Global Tuberculosis Control, World Health Organisation Report, Geneva.

World Health Organisation. (2007). Global Tuberculosis Control. World Health Organisation Report, Geneva. [Online] Available: http://www.who.int/globaltlas/predefinedReport/TB/pdf.

\section{Note}

Note 1. Epidemiological studies usually involve the survey of a defined population. This can be grouped as descriptive, analytical or experimental.

Table 1. Results from the Kruskal-Wallis test

\begin{tabular}{|l|l|}
\hline Kruskal-Wallis chi-squared & 1.4379 \\
\hline Degrees of freedom $(\mathrm{df})$ & 4 \\
\hline p-value & 0.8376 \\
\hline
\end{tabular}

Table 1 above shows the results from the Krustal-Wallis test performed to compare the categorical responses of the respondents to five questions as discussed in subsection (6.8). 